\title{
Situation and Countermeasures for the Construction of Old-age Nursing Care Service System
}

\author{
Yingyan Zhang ${ }^{1}$ \\ ${ }^{1}$ Qiqihar Medical University, China
}

Keywords: nursing care; service system; construction status; countermeasures;

\begin{abstract}
As the aging of the population further intensifies, its impact on the economy and society has become more and more obvious. It also poses new challenges to the construction of the current social pension service system. In order to more accurately establish the social pension service system, this paper analyzes the current status and problems of the current social pension service system, and based on this, proposes to optimize the social pension model, vigorously develop the pension industry, and create a comprehensive range of service platforms and other ways to build an old-age service system that meets the diversified needs of elderly people.
\end{abstract}

\section{Introduction}

With the accelerating rate of population aging and the change in family structure, the issue of family pension is becoming more and more prominent, especially in the care of the elderly. Faced with the needs of nursing care for the elderly, traditional old-age care facilities lack medical service capabilities, and hospitals cannot provide basic old-age services [1]. The "medical support and integration" model can not only relieve the pressure on patients for long-term "pressing beds", but also enable high-quality medical resources. Reasonable use can also solve the medical problems in the process of elderly care.

After entering the 21st century, China's population aging process has entered a period of rapid development. According to statistics, as of the end of 2016, the country's elderly population aged over 60 years was 230 million, accounting for $16.7 \%$ of the total population, the number of elderly population continued to grow, family functions weakened, and care was taken [1]. The problem of nursing has become increasingly prominent, and the training of personnel for the provision of services for the aged has become an important software support for the old-age security system. It is imperative to speed up the construction and construction of services for the aged [1]. However, at present, the status quo of China's old-age care service personnel building is worrying, presenting the phenomenon of scarcity of talents and loss of people, and becoming a weak link in endowment insurance. The number of senior care personnel, their quality, and their stability directly relate to the quality of old-age care services and the vital interests of China's hundreds of millions of elderly people. How to build a professional team of professional nursing care professionals with a sufficient number, high professional level, and good service quality is very urgent for actively responding to the problem of aging and promoting the healthy development of pension services.

\section{The Status Quo and Difficulties of the Development of China's Aged Service Talents}

The first is that the development of old-age care facilities is lagging behind, and there is still a long way to effectively meet the needs of socialized old-age care. Although investment in the construction of facilities for the provision of pension services has been very large in recent years, it still lags behind the actual number of older people and the actual demand for elderly care services. Due to the inadequacy of financial resources at the county level, old-age care services are small in scale, facilities are incomplete, and functions are imperfect [2]. They cannot meet the needs of the elderly in terms of spiritual culture, health care, health and entertainment, etc., and service prices have not changed for many years. Low, the government has no subsidy, coupled with rapid price increases, 
resulting in funding for pension services, and maintaining the status quo is difficult, let alone development.

Second, the development of home-based care services lags behind, and there is a big gap between the growing demand for diversified services for the elderly and the growing needs of the elderly. Due to the failure to integrate home-based care services into the unified planning of community functions, resulting in a general shortage of community aged care service rooms, incomplete service functions, and simple service facilities, development is severely constrained [2]. Most communities can only provide basic services such as dining, entertainment and leisure services. There is a serious lack of equipment and technologies for day care, medical care, rehabilitation care, etc., which has led to difficulties in the development of diversified services and it is difficult to meet the needs of the elderly.

Third, the overall quality of the elderly care service team is low, which is incompatible with the objective requirements for the development of the care services for the aged. The employees in the pension service organizations are generally low in terms of their cultural level, older in age, are seriously lacking professional training skills, have low nursing skills and service levels, and are short of nursing workers and are out of balance with their service counterparts [1].

Fourth, the nursing power of impaired and disabled people is weak. The disability and semi-capacity elderly in the nursing homes account for about $34 \%$ of the total. Cares giving disabled and semi-disabled old people need special nursing skills [2]. Ordinary old-age care institutions are often incompetent. However, the multiple life problems faced by the disabled and semi-disabled old people are still difficult to fundamentally solve completely. According to the data, in 2013, the number of impaired disabled and elderly people in China reached 36 million. According to international standards, elderly disabled persons: The number of nursing staff is 3:1, and about 10 million elderly care workers are needed. However, at the time, only 300,000 workers were engaged in the provision of retirement services in the national welfare agencies, and a sample survey in 2015 showed that 40.63 million disabled and semi-capacity elderly people in China had already reached the age limit. The supply of nursing care workers did not keep up with the increase in demand. As we all know, the "labor shortage" of pension institutions is very common. Many pension institutions in Beijing, Shanghai and other places that we work with have reflected that open nursing homes are uninhabited but elderly care professionals are hard to find. The number of old-age service personnel in most provinces and cities in China is higher than the huge market demand. The gap is very significant. At the same time, the wastage rate is high, with $71 \%$ of the employees working less than 5 years. The loss rate for graduates in the pension industry is $40 \%$ to $50 \%$ in the first year, $60 \%$ to $70 \%$ in the second year, and $80 \%$ to $90 \%$ in the third year.

Fifth, the investment in personnel training is not enough. At present, the government will focus on hardware facilities in the field of pension services, and implement preferential land use, bed subsidies, etc., but for nursing care professionals, whether it is invested from the capital or training less, there is a big gap compared to foreign countries, such as Japan to encourage more students choose to take care of the well-being profession. In this profession, a high-level grant is set up. The government subsidizes $80 \%$. Students only need to pay $20 \%$. At the same time, after graduating from the student who receives the bursary, he will no longer need to return the government's loan as long as he is engaged in the maintenance work for 5 years. In addition, the pension and welfare agencies give an extra RMB 20,000 per month to those who are eligible for welfare. However, most of the old-age care institutions in China have a large gap between their employees receiving a subsidy of 100 $\mathrm{RMB} /$ month for mid-career pensioners.

\subsection{The irrational staff structure and insufficient professionalism.}

1) The composition of personnel is unreasonable. From the perspective of market structure, the current composition of old-age care workers in China is as follows. On the one hand, rural migrant workers, urban laid-off workers, and retirees are the main ones, which are often referred to as "4050" personnel. Academic qualifications are generally low; most of them are junior high schools. And below, and most have not received professional training [3]. On the other hand, graduates from higher 
vocational colleges account for a minority. In China, the construction of old-age nursing talents is relatively late and the development is slow. In 1999, Dalian Vocational and Technical College and Changsha Civil Affairs Vocational and Technical College established the ageing service and management profession, marking the start of the training of China's aged care professionals. According to the latest data from the Ministry of Education, the scale of professional graduates is 1,000 to 1,500 each year, but it is far from the actual needs and the loss is serious. There are also nurses who are transferred to hospitals. 2) The gender structure is irrational. China's old-age care workers are almost exclusively women, and the ratio of men and women is seriously out of balance. 3) The age structure is irrational.

\subsection{The lack of professional skills and the low rate of holding certificates.}

At present, the old-age care institutions mainly use "4050" personnel. However, they basically do not have systematic professional training and do not possess the professional knowledge and skills in nursing technology, social work for the elderly, psychological care, etc., and cannot adapt to changes in the old-age service model, especially existing pensions [3]. Most of the institutional residents are high-income, high- IQ, and highly-educated people. They have higher requirements for the care of the elderly. In addition to basic life care, the spiritual needs are also an important part. In 2014, there were 94,100 various types of elderly care service institutions and facilities across the country, but less than 100,000 people actually had qualification certificates for nursing care workers.

\section{The Construction of Old-age Care Service System}

\subsection{Improve the working mechanism of old-age care services.}

We must give further play to the main roles of the government in the endowment program and improve the working mechanism for the provision of retirement services with "government-led, departmental cooperation, and social participation." First, the party committees and governments at all levels must further raise awareness of the importance of providing elderly care services, include the accelerating development of the care industry for the aged, include economic and social development plans, define work goals, and earnestly implement responsibilities [4]. It is necessary to make overall plans, highlight key points, adapt measures to local conditions, and provide guidance for classification, gradually cultivate and establish the diversified and multi-level urban and rural aged care service systems needed for the development of population aging, and establish and improve the three-tier social pension service guidance centers at county, township, and village levels [4]. The second is to rely on public pension service institutions or construct corresponding pension service platforms to establish a social pension service guidance center with functions of organization, guidance, service, training, etc., and strengthen the management and guidance of pension service organizations and home-based pensions, and gradually form Public pension service institutions are modeled on the basis of urban and rural grassroots welfare service networks, based on home-based pensions, and supplemented with other forms of urban and rural social welfare services.

At the same time, we must actively guide and encourage enterprises and social organizations, especially the individual economy and private economy, to enter the social pension service industry and promote the healthy and orderly development of the pension service industry [5]. The third is to improve the preferential policies for the development of the pension service industry, and to improve the work systems of the departments of civil affairs, finance, planning, construction, human resources and social security, health, land and resources, finance, taxation, and price, and prioritize the use of land for pension institutions. We will reduce or exempt operating taxes and fees, provide support for medical and health services, and increase the credit of the pension service industry to achieve the sustainable development of the pension service industry.

\subsection{Strengthen policy support and form a multi-level professional talent system of nursing care.}

The first is to encourage institutions of higher learning to set up senior service and management professionals and increase their investment. Can refer to normal students training methods, tuition 
fees or high financial aid, etc., while training to stay in the pension industry for a certain number of years to encourage students to apply for and engage in retirement services; second is to reduce the use of free support to the existing pension staff training, improve the rate of forensics can refer to the Shaanxi Provincial Civil Affairs Department to carry out the plan for thousands of elderly care workers, free of training, identification, accommodation and other expenses [5]. At the same time, the current graduates of the senior service and management majors in colleges and universities will only be able to obtain intermediate certificates to senior levels. The third is to encourage the "one professional and two transfer" talent training model. "One specialty" is the training of higher education institutions. "Two transfers" means transferring nursing and other related professional students and those who have been employed, such as women workers or full-time mothers, to the pension service profession through free training or public welfare job subsidies.

\subsection{Increase funding for pension services.}

In the construction of the pension service system, funding is the key to guarantee the orderly implementation of various old-age care services. Adhering to government-led investment and actively seeking support from social forces and charity organizations for the cause of the elderly is an effective way to broaden sources of funds. First, increase public investment in the pension service system. Finances at all levels must continuously increase their investment in the pension service system, including infrastructure construction, equipment support and operating subsidies, and give full play to the guiding and supporting functions of government funds. With the principle of equalization of basic public services, public financial investment is tilted toward low-income groups, and the subsidy standards for low-income groups are raised. Second, we strongly support civil organizations and enterprises in social welfare work. Encourage policies are adopted to attract more civil organizations and enterprises to invest in the pension service system. Governments at all levels must formulate supporting policies and incentive mechanisms in light of actual conditions, guide and encourage social forces such as enterprises, institutions, collective organizations, non-governmental organizations and individuals, and establish pension institutions in various forms such as sole proprietorship, joint ventures, and cooperation. Third, it is necessary to fully mobilize social forces, promote the traditional virtues of respect for the elderly of the Chinese nation, increase the charity awareness of the entire society, innovate methods of fundraising and donation, open up various charitable donation channels, expand sources of welfare funds for the elderly, and encourage all conditions to be met. Individuals and groups promote service and charity, and actively participate in the voluntary work of elderly people of all kinds [2].

\subsection{Strengthen the professional service team for the elderly.}

At present, the professional service needs of nursing care agencies for nursing care and the serious shortage of professional nursing staff are increasingly prominent. There is a serious shortage of professional service personnel in the pension institutions. The government must actively develop community and institutional pension services and other public welfare positions to guide and encourage college graduates, “4050" personnel, zero-employment family members, urban and rural minimum living security personnel, and margins of minimal guarantees [4]. Personnel and other persons with difficulties in finding employment are employed and reemployed in the pension service agencies. To promote the improvement of the level of old-age care services, we will focus on three aspects in the construction of service personnel: First, professional service personnel. Including the professionalization of the knowledge of retirement services and the professionalization are the professional services for the aged. The government co-ordinates knowledge and training for the provision of elderly care services and personnel development plans. It adopts a strict system of certificated employment for social welfare service practitioners and personnel, and conducts on-the-job training in accordance with national occupational standards for nursing care workers. The second is to develop volunteer services. Actively promote volunteer service, publicize volunteer service concept, dedication awareness and civic awareness, and make volunteer service a social fashion and long-term mechanism. The third is to establish a level monitoring mechanism for the 
elderly care service industry. Establish standardized and transparent supervisory procedures, professional and standardized supervision systems, and ensure high quality service levels

\subsection{Strengthen propaganda and change the traditional prejudice of the society for nursing care professionals.}

The first is to use the new media and other channels to publicize the model of outstanding talents in the nursing care industry for the elderly and play an exemplary role. The second is to fundamentally improve entry barriers and wages [3]. The majority of the public's prejudice is based on the traditional belief that "everyone can do it" and "low income", and therefore further strengthen the transfer of qualifications for employees and wage guidance at the same time. The third is to change the name of nursing care workers. The details reflect the attitude, such as Beijing Ocean Hangman old apartment to change its name to "life assistant", nurses generally feel respected, but also more easily accepted.

\section{Conclusion}

The ageing of the population has increased. "Old, who cares for you" is called the focus of social concern. In 2013, the State Council of the People's Republic of China issued the "Some Opinions on Accelerating the Care of the Aged Service Industry" and set off an "endowment fever" in the land of China. It was called the first year of retirement, and the pension service industry received attention. The cultivation of nursing care professionals is the most important task. It is necessary to constantly explore and innovate in order to meet the needs of this emerging industry and promote the further development of China's pension industry.

\section{Acknowledgement}

Projects supported by Qiqihar Municipal Bureau of Science and Technology (Project No.: RKX201524).

\section{References}

[1] R.Zh. Chai and X.Q. Xu, Research on the status quo of city-level nursing staff in the city, Changsha Journal of Civil Administration, 2015, vol.3, pp.18-20.

[2] J.T. Chen, Strengthening the construction of social pension service system Urgently need nursing skills nursing talents, Chinese Civil Policy, 2014, vol.52-9,pp.53.

[3] D.W. Zhao and P.Y. Xiao, Status Quo of Retirement Nursing Talents in China and Approaches to Re-education, Health Vocational Education, 2016, vol.2, pp.93-94.

[4] P.Y. Jie, The development and construction of Chinese Nursing Care Workers, Health vocational education, 2015, vol.4, pp.41-43.

[5] G.T. Lin, Countermeasures for Developing Social Pension Service System, Chinese Civil Policy, 2015, vol.3, pp.15-16 